\title{
SISTEM KOMUNIKASI MASYARAKAT KEPULAUAN DAN KOMPLEKSITAS MULTI ETNIS (Studi Kasus Sistem Komunikasi Masyarakat Kepulauan dan Kompleksitas Multi Etnis di Pulau Sapeken, Kabupaten Sumenep, Madura)
}

\author{
Tatag Handaka \\ Prodi Ilmu Komunikasi, FISIB-Universitas Trunojoyo Madura \\ Email: tatag.handaka@trunojoyo.ac.id
}

\begin{tabular}{ll} 
ARTICLE INFO & ABSTRACT \\
\hline & $\begin{array}{l}\text { The society of Sapeken islands are multi ethnic society. They're multicultural } \\
\text { society. The aim of the research is to know about Sapeken's society communication } \\
\text { system to encounter multi ethnic complexities. The theory of the research is }\end{array}$ \\
& communication system in Niklas Luhmann perspective. The research used case \\
study method. The result of the research shown that society communication system \\
Keywords: & has produced and reproduced information to encounter environmental \\
System; Information & complexities about multi ethnic. Information which produced by system are \\
Production; Information & collective fish selling, collective purchasing foods and beverages, and religious \\
Reproduction; & activities. Information which produced by society communication system was \\
Government & effective to solve multi ethnic complexities. Government communication system \\
Communication System. & have not produced information related to multi ethnic complexities.
\end{tabular}

\section{PENDAHULUAN}

Madura memiliki 127 pulau, satu pulau berada di kabupaten Sampang, yaitu pulau Mandangin. Tapi masyarakat lebih sering menyebutnya sebagai pulau Kambing. Seratus dua puluh enam pulau lainnya berada di kabupaten Sumenep. Diantara 126 pulau tersebut, yang paling besar wilayahnya adalah pulau Kangean. Pulau ini terdiri dari tiga kecamatan. Pulau yang paling padat penduduknya adalah Sapeken. Pulau ini terdiri dari satu kecamatan, yaitu kecamatan Sapeken. Pulau ini berbatasan dengan laut Jawa di sebelah barat, laut Sulawesi di sebelah timur, laut Kalimantan di sebelah utara, dan laut Bali di sebelah selatan.

Kecamatan Sapeken bukan hanya terdiri dari pulau Sapeken, tapi ada 53 pulau yang masuk dalam wilayah administrasinya. Ada 21 pulau yang sudah berpenghuni dan 32 pulau yang belum berpenghuni. Masyarakat Madura yang ingin bepergian ke pulau Sapeken, biasanya berangkat dari pelabuhan Kalianget (Sumenep). Mereka naik kapal dari Kalianget ke pulau Kangean. Kapal dari Kalianget ada yang disediakan oleh penduduk (kapal motor atau kapal ekspress) dan PT PELNI. Setelah sampai Kangean, perjalanan dilanjutkan melalui daratan, melintasi pulau Kangean, kemudian naik kapal motor dari dermaga menuju pulau Sapeken.

Bangunan rumah warga pulau Sapeken rata-rata berbentuk panggung (berkaki). Bentuk rumah ini untuk menghindari banjir ketika air laut sedang pasang. Alat transportasi masyarakat antara lain sepeda motor, sepeda, dan odong-odong. Alat transportasi yang terakhir sering hilir-mudik di jalanjalan dan gang-gang di pulai ini. Ada mobil untuk operasional kantor kecamatan dan beberapa yang lain dimiliki masyarakat. Letak pulau Sapeken dijelaskan dalam gambar 1: 


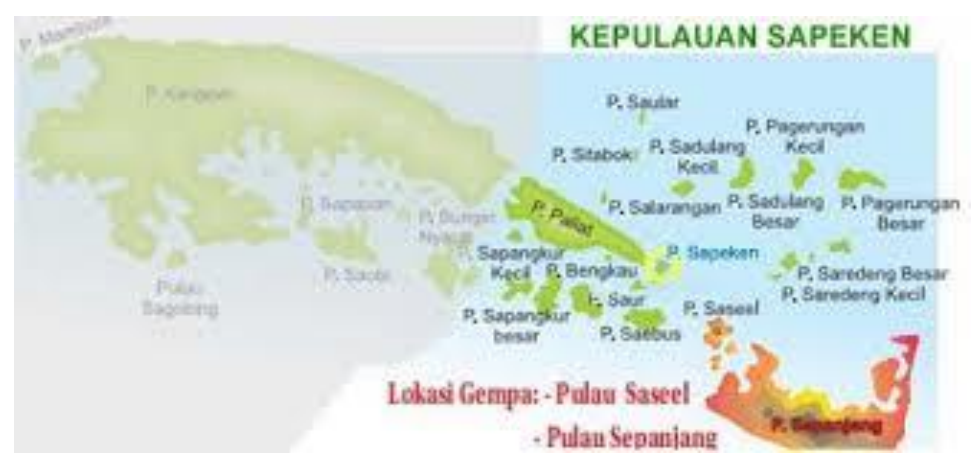

\section{Gambar 1. Peta Pulau Sapeken}

Masyarakat pulau Sapeken adalah multikultural, terdiri dari suku Madura, Bajo Mandar, dan Bugis. Keempat suku masyarakat ini semula hanya singgah di pulau Sapeken ketika menangkap ikan. Nelayan hanya menginap beberapa hari untuk kemudian melanjutkan pelayaran berikutnya. Masyarakat dari berbagai suku silih berganti singgah dan tinggal di pulau ini. Pulau yang semula tidak berpenghuni lama-kelamaan digunakan sebagai tempat tinggal para nelayan. Tempat untuk menambatkan kapal di pantai pulau Sapeken yang biasa digunakan nelayan dari berbagai suku ketika singgah dulu, masih digunakan hingga sekarang.

Mudah dipahami, bila hingga sekarang, mayoritas pekerjaan penduduk Sapeken adalah nelayan. Masyarakat nelayan dari suku Bajo Mandar, dan Bugis berbaur dengan nelayan Madura. Interaksi masyarakat antar suku selama bertahun-tahun, telah membentuk masyarakat multi etnis. Budaya masyarakat pulau Sapeken beda dengan budaya masyarakat Madura. Bahasa yang digunakan masyarakat pulau Sapeken juga jelas berbeda dengan bahasa Madura.

Masyarakat pulau Sapeken menghadapi kompleksitas lingkungan multi etnis dalam sejarah pembentukannya. Bila dulu terjadi konflik antar etnis, mungkin masyarakat Sapeken tidak bisa bertahan hingga saat ini. Konteks inilah yang diteliti dalam paper ini, tentang sistem komunikasi masyarakat pulau Sapeken dalam menghadapi kompleksitas multi etnis.

\section{TINJAUAN PUSTAKA}

Penelitian tentang sistem pernah dilakukan sebelumnya. Fokus penelitian sistem pada aspek integrasi (Asrinaldi dan Yoserizal, 2013; Wahyuningsih, 2011). Sistem dilihat sebagai proses pengintegrasian berbagai sub sistem yang ada di dalamnya. Sistem sebagai proses integrasi lebih ditekankan pada perilaku aktor dalam merespons berbagai persoalan yang dihadapi. Perspektif ini menempatkan sistem dalam level mikro.

Penelitian tentang sistem berikutnya berkaitan dengan revitalisasi (Wicaksono, 2012; Syam, 2003; Haryanah, 2004; Abbas dan Manan, 2005; Sosiawan, et al., 2013; Lestari, et al., 2013). Fokus penelitian ini adalah meningkatkan peran penting sistem dalam menyelesaikan persoalan dirinya. Penelitian ini juga menggali peran strategis sistem yang pernah berhasil dalam menjalankan fungsinya. Penelitian dalam bidang revitalisasi lebih menekankan pada struktur. Fokus penelitian akhirnya cenderung pada peningkatan peran penting struktur.

Tema penelitian sistem selanjutnya berkaitan dengan representasi (Sosiawan dan Wibowo, 2015; Husain, 2011). Fokus penelitian ini menelisik tentang makna sesuatu yang dihadirkan melalui sesuatu yang lain. Sistem berpotensi untuk menghadirkan makna sebuah realitas dengan medium lain, misalnya media online.

Penelitian ini masih terbatas pada eksplorasi media yang menjadi perantara atau penyampai makna atas realitas. Sistem hanya dipahami hanya sebatas instrumen untuk memediasi berbagai makna yang diinginkan oleh komunikator. Makna bisa didesain sesuai dengan kepentingan produsen pesan. Perspektif ini cenderung menempatkan sistem dalam ruang media sebagai proses linear, padahal media sudah bergerak ke arah konvergensi.

Penelitian tentang sistem juga berkaitan dengan partisipasi (Sulistyowati dan Dibyorin, 2013; Budi, 2012). Fokus penelitian pada aspek sistem yang diteliti masih terbatas pada koordinasi, informasi, dan kerjasama. Penelitian ini belum mengeksplorasi proses lahirnya informasi yang dihasilkan sistem. Penelitian tentang sistem juga lebih menekankan pada strukturnya. 
Penelitian selanjutnya tentang sifat sistem yang tertutup (Nobles dan Schiff, 2004; Neves, 2001; Rothchild, 2009; Hessling dan Pahl, 2006; Besio dan Pronzini, 2011; von Groddeck, 2011; Stichweh, 2000). Fokus penelitian ini menekankan pada sistem yang membatasi diri dari lingkungan. Sistem yang menentukan zona dirinya agar bisa dibedakan dengan lingkungan. Penelitian ini belum mengeksplorasi tentang strategi sistem dalam menentukan zona atau batas dirinya. Aspek yang mendorong sistem bersifat tertutup juga belum ditelisik lebih jauh.

Penelitian berikutnya tentang sistem dan diferensiasi (Osterberg, 2000; Borch, 2005; Vanderstraeten, 2004; Lee, 2000). Fokus penelitian ini tentang sistem yang mendiferensiasi dirinya ketika menghadapi persoalan yang dihadapi. Penelitian lebih ditekankan pada diferensiasi fungsi, belum mengeksplorasi struktur yang menyertainya.

Penelitian tentang sistem komunikasi Pemerintah pernah dilakukan pada pengembangan kambing Peranakan Ettawa (PE) di kabupaten Purworejo (Handaka, et.al., 2016a; Handaka, et.al., 2016b). Penelitian tentang masyarakat sebagai sistem-sistem autopoiesis (Hardiman, 2008: 1-15; Sitorus, 2008: 17-36). Teori yang digunakan dalam penelitian ini adalah sistem komunikasi dalam perspektif Niklas Luhmann.

\section{METODE PENELITIAN}

Metode penelitian yang digunakan adalah studi kasus (case study). Proses penelitian case study meliputi tahap: pengumpulan data mentah (assemble the raw case data), mengkonstruksi data (construct a case record), menulis narasi (write a final case study narrative) (Patton, 2002: 450). Tahap pertama merupakan pengumpulan data yang terdiri dari seluruh informasi tentang orang, program, organisasi atau latar studi kasus yang ditulis. Tahap kedua adalah reduksi data mentah atas kasus yang telah diorganisasi, diklasifikasi dan diedit ke dalam file yang tertata dan mudah diakses.

Tahap ketiga ialah studi kasus sudah terbaca, gambaran deskriptif atau cerita tentang orang, program, organisasi, dan lainnya, membuat semua informasi itu mudah diakses pembaca untuk memahami kasus dalam seluruh keunikannya. Cerita tentang kasus dapat dikatakan secara kronologis atau disajikan secara tematis (kadang keduanya).

Studi kasus menawarkan gambaran holistik, disajikan dengan beberapa konteks penting untuk memahami kasus. Presentasi data sebisa mungkin menyertakan respon/non verbal informan (Darlington \& Scott, 2002: 29).

Populasi penelitian di kepulauan Sapeken. Sampel yang diambil adalah kecamatan Sapeken yang terdiri dari sembilan desa. Teknik sampel menggunakan purposive (purposive sampling). Peneliti memilih informan sesuai dengan tujuan dan kepentingan untuk mendapat informasi tentang sistem komunikasi masyarakat. Informan penelitian terdiri dari 2 tokoh agama, 2 tokoh masyarakat, 1 nelayan, Camat, Sekretaris Desa, dan 2 mahasiswa. Total jumlah informan penelitian sebanyak 9 orang. Informan ini dipilih karena memiliki informasi yang banyak (rich information) tentang sistem komunikasi masyarakat.

Peneliti mengambil data penelitian dengan wawancara dan observasi. Wawancara dilakukan berdasarkan pedoman wawancara (interview guide) yang sudah disusun sebelumnya. Wawancara ke tokoh masyarakat dan tokoh agama dilakukan di rumah. Wawancara dengan aktor pemerintah dilakukan di kantor desa dan kecamatan. Pengamatan penelitian meliputi perilaku masyarakat yang berkaitan dengan persoalan sistem komunikasi. Peneliti tinggal di pulau Kangean dan Sapeken selama satu pekan.

Data primer yang diperoleh dari wawancara kemudian diklasifikasikan sesuai isu dalam sistem komunikasi. Data observasi dicatat dalam buku catatan lapang. Kedua jenis data ini digunakan sebagai dasar untuk analisis dan diskusi. Pembahasan dan diskusi atas temuan data menggunakan teori sistem komunikasi dalam pespektif Niklas Luhmann.

\section{HASIL DAN DISKUSI}

\subsection{Sistem Komunikasi Masyarakat}

Pulau Sapeken adalah potret masyarakat multikultural. Masyarakat yang telah menghuni dan menetap selama bertahun-tahun di pulau ini, berasal dari beragam suku. Masyarakat pulau Sapeken selain berasal dari suku Madura, juga dari Bugis, Mandar, dan suku Bajo. Proses interaksi, interrelasi, dan komunikasi dalam waktu lama, telah membentuk dan "melahirkan" mereka dalam sebuah masyarakat dengan corak sosio-kultural yang "baru". Sebagai masyarakat maritim, pekerjaan utama 
mereka adalah nelayan. Jalur dan jangkauan wilayah tangkapan ikan meliputi laut Jawa hingga perairan Makasar. Kehidupan sosial budaya masyarakat sehari-hari, menunjukkan identitas multi etnis, multikultur.

Masyarakat pulau Sapeken memiliki bahasa yang mirip dengan bahasa Madura. Namun bahasa masyarakat di pulau ini berbeda dengan bahasa Madura yang ada di kabupaten Bangkalan, Sampang, Pamekasan, dan Sumenep. Bahasa masyarakat pulau Sapeken memiliki lema yang berbeda dengan bahasa Madura di keempat kabupaten itu. Selain lema, dialek bahasa masyarakat Sapeken juga berbeda dengan bahasa Madura pada umumnya.

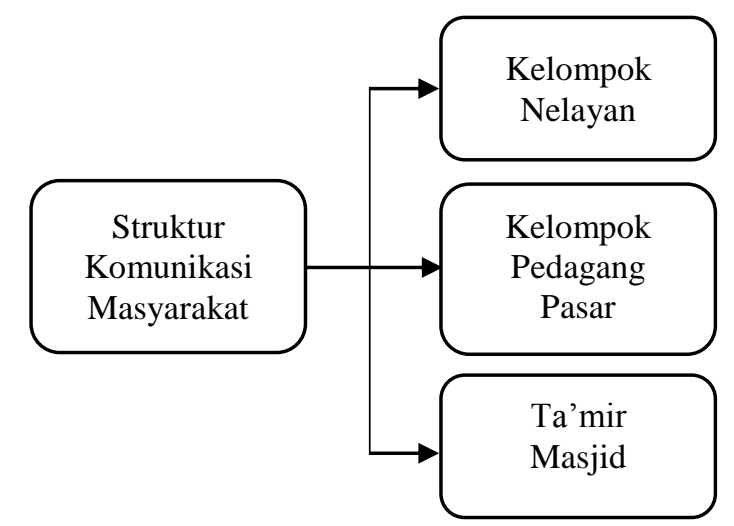

\section{Gambar 2.Struktur Komunikasi Masyarakat}

Masyarakat pulau Sapeken memiliki sistem dan struktur. Struktur komunikasi masyrakat misalnya bisa dijumpai pada kelompok nelayan, kelompok pedagang pasar, dan ta'mir masjid (gambar 2). Ta'mir masjid yang berfungsi untuk mengkoordinasi jamaah dalam kegiatan pengajian, tahlilan, dan yasinan. Sistem komunikasi masyarakat merupakan fungsi dari struktur. Tiap stuktur, akan senantiasa disertai dengan sistem dalam dirinya.

Bahasa masyarakat Sapeken yang berbeda dengan bahasa Madura merupakan salah satu tanda bahwa sistem bersifat terbuka dan sekaligus tertutup. Sistem mengambil informasi (lema, dialek/logat, diksi) dari lingkungan, yang menandakan bahwa sistem bersifat terbuka. Namun sistem memiliki ciri khas yang membedakannya dari lingkungan (lema, dialek/logat bahasa), ini merupakan sifat sistem tertutup. Sistem komunikasi masyarakat masih menunjukkan eksistensi diri sebagai multi etnis, multikultural.

Sistem komunikasi masyarakat yang bersifat terbuka dan sekaligus tertutup, menunjukkan bahwa ada kompleksitas dalam lingkungan. Kompleksitas lingkungan akan senantiasa meniscaya dalam diri tiap sistem. Salah satu kompleksitas lingkungan yang dihadapi sistem masyarakat pulau Sapeken adalah multi etnis (garis putus-putus). Kompleksitas sistem masyarakat dijelaskan dalam gambar 3:

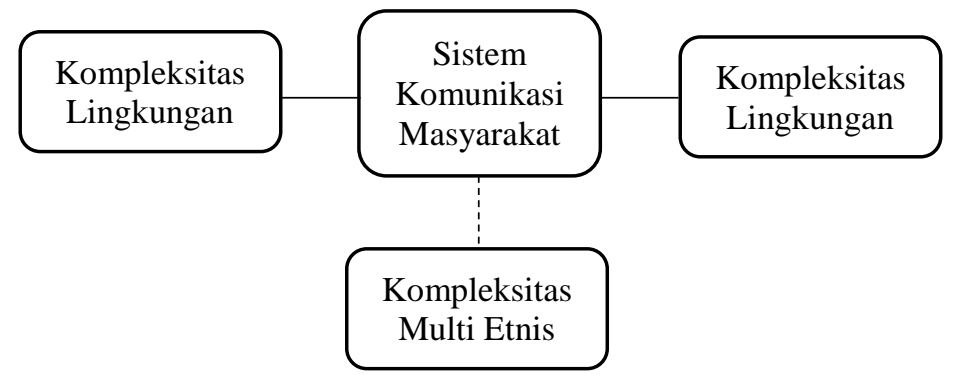

\section{Gambar 3. Sistem Komunikasi Masyarakat dan Komplesitas Multi Etnis}

Sistem komunikasi masyarakat berada di tengah kompleksitas lingkungan. Kompleksitas lingkungan terdiri dari tuntutan dan tantangan lingkungan yang dihadapi sistem komunikasi masyarakat. Lingkungan menyediakan banyak informasi, tapi masih bersifat tidak pasti, tidak jelas, dan tidak terprediksi (equivocality). Sistem komunikasi masyarakat bertugas untuk menyeleksi dan mereduksi informasi lingkungan sehingga menjadi lebih pasti, jelas, dan terprediksi.

Sistem masyarakat dalam menghadapi kompleksitas multi etnis telah memproduksi dan mereproduksi informasi. Sistem memproduksi informasi untuk menyelesaikan kompleksitas yang 
dihadapi. Informasi yang diproduksi adalah penjualan ikan secara bersama-sama, pembelian sembilan bahan pokok (sembako) secara kolektif, dan acara keagamaan (misalnya pengajian, tahlilan, serta yasinan). Produksi dan reproduksi informasi yang dilakukan sistem komunikasi masyarakat dijelaskan dalam gambar 4:

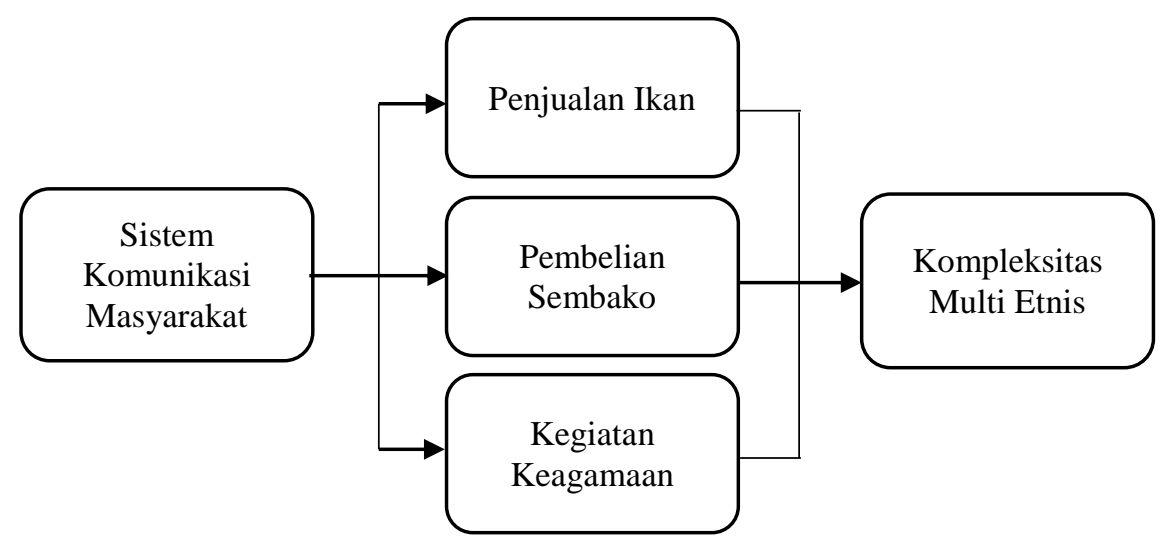

\section{Gambar 4. Sistem Komunikasi Masyarakat dan Produksi Informasi}

Informasi yang diproduksi sistem komunikasi masyarakat untuk menyelesaikan kompleksitas multi etnis adalah penjualan ikan secara bersama-sama. Sebagian besar pekerjaan masyarakat pulau Sapeken adalah nelayan. Ikan hasil tangkapan nelayan jarang dijual di pasar Sapeken atau pasar Kalianget (Sumenep), tapi dijual ke Probolinggo atau Bali (terutama pasar ikan di kota Singaraja). Nelayan menjual hasil tangkapan ikan secara bersama-sama ke pasar Singaraja karena hanya membutuhkan waktu tempuh sekitar 1-2 jam.

Informasi lain yang diproduksi sistem komunikasi masyarakat adalah pembelian sembako secara bersama. Masyarakat nelayan Sapeken membeli sembako dari pedagang Probolinggo dan Banyuwangi. Nelayan Sapeken menjual ikan dan pedagang Probolinggo atau Banyuwangi menyediakan bahan makanan seperti beras, minyak, telor, tepung dan lain-lain. Nelayan Sapeken juga membeli kebutuhan bahan bakar solar untuk kapal ke pedagang Probolinggo atau Banyuwangi. Nelayan Sapeken memang lebih sering berinteraksi dan bertransaksi ekonomi dengan pedagang atau nelayan dari Banyuwangi, Bali dan Probolinggo dibanding dengan nelayan Sumenep.

Sistem komunikasi masyarakat dalam menghadapi kompleksitas multi etnis juga memproduksi informasi tentang kegiatan keagamaan. Mayoritas masyarakat sapeken adalah warga Nahdhatul Ulama (NU). Masyarakat melakukan kegiatan kegamaan secara rutin, misalnya pengajian, tahlilan dan yasinan. Kegiatan ini dilakukan secara bergiliran dari satu rumah ke rumah lain. Masyarakat mengadakan pengajian misalnya pada hari besar keagamaan (peringatan 1 Muharram, Nuzulul Qur'an, Maulid Nabi, atau Haul). Masyarakat mengadakan tahlilan dan yasinan dalam hajathajat tertentu.

Informasi yang diproduksi ini mempertemukan masyarakat dalam momen-momen penting. Tiap anggota masyarakat sadar menjadi bagian dari komunitas atau kelompoknya. Masyarakat menghadapi persoalan multi etnis dalam kehidupan mereka sehari-hari. Bauran antara suku Madura, Bugis, Bajo, dan Mandar. Masyarakat harus mengatasi multi etnis ini untuk mencapai tujuan yang lebih besar, kehidupan sosial ekonomi dan budaya.

Berbagai informasi yang diproduksi sistem efektif untuk mengatasi kompleksitas multi etnis. Penjualan ikan membuat masyarakat nelayan Sapeken bersatu dan melampaui multi etnis dalam diri mereka. Penjualan hasil tangkapan ikan untuk mendapatkan keuntungan lebih besar telah mengalahkan potensi konflik yang disebabkan beda etnis. Tujuan ekonomi membuat mereka memiliki tujuan sama dalam pekerjaan sebagai nelayan.

Pembelian sembako secara bersama juga efektif menyelesaikan tuntutan dan tantangan lingkungan yang berupa multi etnis. Pembelian sembako secara bersama ini dilakukan masyarakat baik dalam kondisi normal atau kelangkaan sembako. Masyarakat sudah berulangkali menghadapi kelangkaan beberapa jenis sembako, misalnya beras, telur, atau minyak goreng. Masyarakat juga beberapa kali mengalami kelangkaan bumbu makanan, misalnya bawang merah, bawang putih, atau cabai. Pembelian sembako secara bersama-sama membuat masyarakat merasa senasib sepenanggungan. Masyarakat dihadapkan pada persoalan riil yang dekat di hadapan mereka. 
Persoalan kelangkaan sembako, jamak dirasakan masyarakat kita. Namun persoalan ini akan semakin terasa "mengancam" bagi masyarakat Sapeken atau masyarakat kepulauan pada umumnya. Masyarakat Madura (Bangkalan, Sampang, Pamekasan, dan Sumenep) yang mengalami kelangkaan sembako panik, tapi bagi masyarakat Sapeken akan terasa lebih panik. Masyarakat Madura masih mudah terhubung dengan daerah lain (Jawa), tapi masyarakat Sapeken tidak mudah terhubung dengan daerah lain, terpisah dengan lautan yang butuh waktu berjam-jam untuk melaluinya.

Kegiatan keagamaan adalah aktifitas di darat yang mendorong kohesivitas masyarakat Sapeken. Kegiatan keagamaan ramai dikunjungi masyarakat. Pengajian yang diadakan ramai dihadiri Bapak-Bapak dan Ibu-Ibu. Tokoh agama (Kyai atau Ustadz) memegang peran penting dalam kegiatan ini. Kegiatan keagamaan juga telah melampaui kompleksitas multi etnis yang meniscaya dalam diri masyarakat.

Produksi dan reproduksi informasi menandai adaptasi sistem terhadap kompleksitas lingkungan. Sistem tentu tidak bisa menyelesaikan seluruh persoalan yang ia hadapi. Sistem akan menyeleksi dan mereduksi informasi lingkungan yang menjadi perhatian utamanya. Kompleksitas lingkungan berupa sifat multi etnis telah menjadi perhatian masyarakat Sapeken. Sistem berusaha untuk menyelesaikan tuntutan dan tantangan riil masyarakat kepulauan ini.

Sistem harus bisa membedakan diri dengan lingkungan. Sistem tidak boleh lebih kompleks dari lingkungan (Luhmann, 1995: 128; Luhmann, 1992: 251-259). Bila sistem tidak bisa mendiferensiasi dirinya dengan lingkungan, maka ia akan larut dalam lingkungan. Sistem yang tidak mendiferensiasi diri dan larut dalam lingkungan, ia akan musnah. Sistem sudah tidak bisa lagi dibedakan dengan lingkungan.

\subsection{Sistem Komunikasi Masyarakat vs Pemerintah}

Masyarakat Sapeken selain memiliki sistem komunikasi masyarakat, juga sistem komunikasi Pemerintah. Sistem komunikasi Pemerintah bisa diketahui dari struktur yang ada di kecamatan dan desa. Pulau Sapeken hanya terdiri dari satu kecamatan, yaitu kecamatan Sapeken. Kecamatan Sapeken terdiri dari sembilan desa. Kecamatan lain yang dekat dengan Sapeken adalah tiga kecamatan yang ada di pulau Kangean.

Sistem komunikasi Pemerintah dijalankan oleh struktur yang ada di kecamatan. Aktor utama dalam sturktur komunikasi Pemerintah adalah Camat dan Sekretaris Camat (Sekcam). Sistem komunikasi Pemerintah dijelaskan dalam gambar 5:

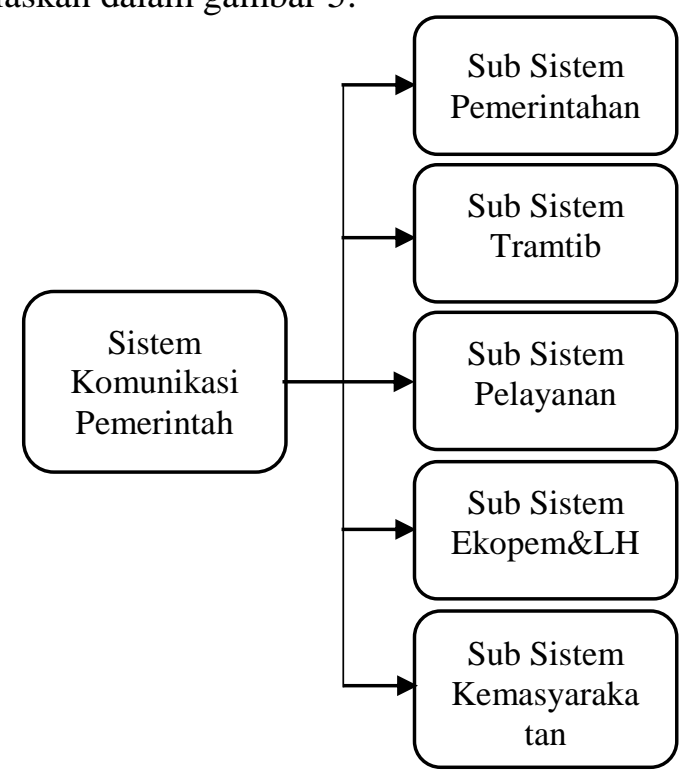

\section{Gambar 5. Sistem Komunikasi Pemerintah}

Sistem komunikasi Pemerintah terdiri dari lima sub sistem. Masing-masing sub sistem memiliki fungsi khusus dalam produksi dan reproduksi informasi. Sub sistem pemerintahan yang memproduksi informasi terkait dengan sistem komunikasi yang ada di desa. Sistem komunikasi Pemerintah juga menghadapi kompleksitas lingkungan sendiri, yang bisa jadi kompleksitas yang dihadapi sistem komunikasi masyarakat belum menjadi perhatiannya. 
Sistem komunikasi Pemerintah belum banyak memproduksi informasi terkait kompleksitas multi etnis yang dihadapi sistem komunikasi masyarakat. Sistem komunikasi Pemerintah telah memproduksi informasi berupa pendirian pasar, jalan, listrik, bangunan fisik dermaga kapal yang ada di desa Sapeken, dan fasilitas umum lainnya. Pasar kecamatan terdiri dari kios-kios papan berjejer. Letak pasar dan dermaga di desa ini berdekatan. Sistem komunikasi Pemerintah dan sistem komunikasi masyarakat belum berinterrelasi dalam kompleksitas multi etnis.

Kedua sistem belum berinterrelasi terkait produksi informasi berupa penjualan ikan dan pembelian sembako. Kapal yang digunakan dalam penjualan ikan dan pembelian sembako adalah milik nelayan. Interrelasi sistem komunikasi Pemerintah dan sistem komunikasi masyarakat terjadi ketika ada kegiatan keagamaan. Terutama kegiatan yang berskala besar, misalnya perayaan Idul Fitri atau Idul Adha.

\section{SIMPULAN}

Masyarakat pulau Sapeken memiliki struktur dan sistem komunikasi. Struktur komunikasi masyarakat ditemukan dalam bentuk kelompok nelayan, ta'mir masjid yang biasanya mengelola kegiatan jamaah untuk pengajian/tahlilan/yasinan, dan kelompok pedagang pasar. Sistem komunikasi masyarakat menghadapi berbagai kompleksitas lingkungan. Salah satu kompleksitas lingkungan yang dihadapi sistem komunikasi masyarakat adalah realitas multi etnis. Sistem komunikasi masyarakat telah memproduksi dan mereproduksi informasi untuk menyelesaikan kompleksitas tersebut. Informasi yang diproduksi meliputi penjualan ikan secara bersama, pembelian sembako secara kolektif, dan kegiatan keagamaan. Informasi yang diproduksi sistem komunikasi masyarakat efektif menyelesaikan kompleksitas multi etnis. Sistem komunikasi Pemerintah belum memproduksi informasi terkait kompleksitas multi etnis.

\section{UCAPAN TERIMA KASIH}

Penulis mengucapkan terima kasih pada Direktorat Riset dan Pengabdian Masyarakat (DRPM) Kementerian Riset, Teknologi, dan Pendidikan Tinggi (Kemenristekdikti) yang telah membiayai penelitian ini melalui skema Penelitian Hibah Bersaing (PHB). Peneliti juga mengucapkan terima kasih pada Ketua Pengurus Cabang NU pulau Kangean yang telah menyediakan tempat menginap selama peneliti mengambil data penelitian di kepulauan timur Madura.

\section{DAFTAR PUSTAKA}

Abbas, T. dan Manan, W.K., 2005, "Keterkaitan antara Demokrasi Politik, Demokrasi Ekonomi dan Sistem Ekonomi Kerakyatan”, Jurnal Mimbar, Vol. XXI, No. 3, hal. 430-440.

Asrinaldi dan Yoserizal, 2013, "Ancaman terhadap Pengembangan Sistem Pertahanan Sosial Daerah Perbatasan di Kota Batam", Jurnal Mimbar, Vol. 29, No. 1, hal. 1-10.

Besio, C. and Pronzini, A., 2011, "Inside Organizations and Out: Methodological Tenets for Empirical Research Inspired by Systems Theory”, Journal of Historical Social Research, Vol. 36, No. 1, hal. 18-41.

Borch, C., 2005, "Systemic Power: Luhmann, Foucault, and Analytics of Power", Acta Sociologica, Vol. 48, No. 2, hal. 155-167.

Budi HH., S., 2012, "Komunikasi Bencana: Aspek Sistem (Koordinasi, Informasi, dan Kerjasama)", Jurnal Komunikasi ASPIKOM, Vol. 1, No. 4, hal. 363-372.

Darlington, Y. and Scott, D., 2002, Qualitative Research in Practice: Stories from the Field, New South Wales: Allen \& Unwin.

Handaka, T., Wahyuni, H.I., Sulastri E. dan Wiryono, P., 2016a, "The Complexity of Government Communication System in Ettawa Crossbred (EC) Goat Farming in Purworejo". Mimbar: Social and Development Journal, Vol. 3, No. 1, hal. 88-96.

Handaka, T., Wahyuni, H.I., Sulastri, E. dan Wiryono, P., 2016b, "Sistem Komunikasi Pemerintah dan Kompleksitas Ikon Kambing PE di Kabupaten Purworejo". Jurnal Ilmu Komunikasi, Vol. X, No. 2, hal. 180-189.

Hardiman, F.B., 2008, “Teori Sistem Niklas Luhmann”, Jurnal Filsafat Driyarkara, Th. XXIX, No. 3, hal. 1-15. 
Haryanah, N., 2004, "Rekonstruksi Sistem Pendidikan di Indonesia sebagai Upaya Meningkatkan Kualitas Bangsa", Jurnal Mimbar, Vol. XX, No. 4, hal. 540-554.

Hessling, A. and Pahl, H., 2006, "The Global System of Finance: Scanning Talcott Parson and Niklas Luhmann for Theoretical Keystones", Journal of Economics and Sociology, Vol. 65, No. 1, hal. 189-218.

Husain, F., 2011, "Sistem Budaya Bahari Komunitas Nelayan Lungkak Desa Tanjung Luar, Lombok Timur, Nusa Tenggara Barat", Jurnal Komunitas, Vol. 3, No. 1, hal. 40-50.

Lee, D., 2000, "The Society of Society: The Grand Finale of Niklas Luhmann", Journal of Sociological Theory, Vol. 18, No. 2, hal. 320-330.

Lestari, P., Sembiring, I.D.P.Br., Prabowo, A., Wibawa, A. dan Hindariningrum, R., 2013, "Manajemen Komunikasi Bencana Gunung Sinabung 2010 Saat Tanggap Darurat". Jurnal Ilmu Komunikasi, Vol. 10, No. 2, hal. 139-157.

Leydesdorff, L, 2000, "Luhmann, Habermas, and the Theory of Communication", Systems Research and Behavioral Science, Vol. 17. No. 3, hal. 273-288.

Luhmann, N., 1992, "What is Communication", Journal of the International Communication Association, Vol. 2, Issue 3, hal. 251-259.

Luhmann, Niklas, 1995, Social Systems, Translated by John Bednarz Jr. with Dirk Baecker, Stanford: Stanford University Press.

Neves, M., 2001, "From the Autopoiesis to the Allopoiesis of Law", Journal of Law and Society, Vol. 28, No. 2, hal. 242-264.

Nobles, R. and Schiff, D., 2004, "A Story of Miscarriage: Law in the Media", Journal of Law and Society, Vol. 31, No. 2, hal. 221-244.

Osterberg, D., 2000, “Luhmann's General Sociology”, Acta Socilogica, Vol. 43, No. 1, hal. 15-25.

Patton, M.Q., 2002, Qualitative Research and Evaluation Methods, $3^{\text {rd }}$ Edition, California: SAGE Publications, Inc.

Rothchild, J., 2009, "Law, Religion, and Culture: The Function of System in Niklas Luhmann and Kathryn Tanner", Journal of Law and Religion, Vol. 24, No. 2, hal. 475-506.

Sitorus, F.K., 2008, "Masyarakat sebagai Sistem-Sistem Autopoiesis: Tentang Teori Sistem Sosial Niklas Luhmann", Jurnal Filsafat Driyarkara, Th. XXIX, No. 3, hal. 17-36.

Sosiawan, E.A., Nugroho, A.R.B., Susilastuti, DN., 2013, "Model Manajemen Teknologi Komunikasi dalam Pemerintahan dan Penanganan Bencana Alam", Jurnal Ilmu Komunikasi, Vol 11, No. 1, hal. 1-16.

Sosiawan, E.A. dan Wibowo, R., 2015, "Representasi Politik Identitas dalam Kampanye Online Calon Legislatif Partai Politik Peserta Pemilu 2014", Jurnal Ilmu Komunikasi, Vol. 13, No. 3, hal. 234-248.

Stichweh, R., 2000, "Systems Theory as an Alternative to Action Theory: The Rise of 'Communication' as a Theoretical Option", Acta Socilogica, Vol. 43, No. 1, hal. 5-13.

Sulistyowati, F. dan Dibyorin, C.R., 2013, "Partisipasi Warga Terhadap Sistem Informasi Desa". Jurnal Komunikasi ASPIKOM, Vol. 2, No. 1, hal. 579-588.

Syam, N.K., 2003, "Mencari Format Sistem Pemilu yang Berkualitas", Jurnal Mimbar, Vol. XIX, No. 1, hal. 23-32.

Vanderstraeten, R., 2004, "The Social Differentiation of the Educational System", Journal of Sociology, Vol. 38, No. 2, hal. 255-272.

Von Groddeck, V., 2011, "The Case of Value Based Communication: Epistemological and Methodological Reflections from a System Theoretical Perspective", Journal of Historical Social Research, Vol. 36, No. 1, hal. 66-86.

Wahyuningsih, T., 2011, "Sistem Bagi Hasil Maro sebagai Upaya Mewujudkan Solidaritas Masyarakat", Jurnal Komunitas, Vol. 3, No. 2, hal. 197-204.

Wicaksono, D.A., 2012, "Revitalisasi Sumber Daya Manusia Polri untuk Sinergitas Kinerja dalam Integrating Criminal Justice System", Jurnal Makara: Sosial Humaniora, Vol. 16, No. 2, hal. 135-149. 